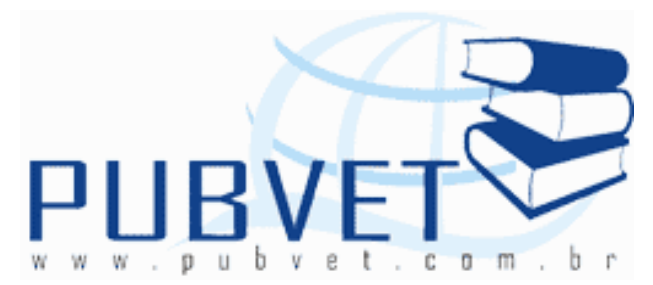

PUBVET, Publicações em Medicina Veterinária e Zootecnia.

\title{
Efeito do transporte na qualidade e rendimento da carne
}

\author{
Angela Aparecida da Fonseca ${ }^{1 *}$; Vinicius Lopes Tomé2 ; Marcell Patachi \\ Alonso $^{3}$; Anderson de Moura Zanine ${ }^{4}$, Fagton de Mattos Negrão ${ }^{5}$, Larissa \\ Cardoso Feijó ${ }^{1}$
}

1 Mestranda em Ciência Animal, Universidade Federal do Mato Grosso. Av. Fernando Corrêa da Costa, no 2367 - Bairro Boa Esperança. CEP 78060-900. Cuiabá, MT. Brasil. *Correspondência: angelaapfonseca@hotmail.com

'Zootecnista na empresa CSA GENÉTICA BOVINA (CABANHA SANT' AGATA), Pontes e Lacerda - MT, Brasil.

3 Departamento de Zootecnia, Universidade Federal de Mato Grosso, Rondonópolis - MT, Brasil.

${ }^{4}$ Professor interino da Universidade Estadual do Mato Grosso, Pontes e Lacerda - MT.

${ }^{5}$ Doutorando em Ciência Animal, Universidade Federal de Mato Grosso, Cuiabá - MT, Brasil.

\section{Resumo}

O efeito do transporte na qualidade e rendimento da carne determina a eficiência da produção de bovinos, os quais são dependentes de ações que se inicia desde o embarque na fazenda até ao desembarque dos animais no frigorifico. Portanto genética, manejo sanitário e manejo alimentar não são 
FONSECA, A.A. et al. Efeito do transporte na qualidade e rendimento da carne. PUBVET, Londrina, V. 8, N. 5, Ed. 254, Art. 1682, Março, 2014.

suficientes para garantir qualidade e rendimento da carcaça se boas praticas no transporte não forem adotadas.

Palavras-chave: produção, carcaça, bovinos

\title{
Effect of transport on meat quality and yield
}

\begin{abstract}
The effect of transport on meat quality and yield determines the efficiency of cattle, which are dependent on actions which starts from boarding to landing in farm animals in the refrigerator. So genetics, health management and feed management are not sufficient to ensure quality and carcass yield was good practices in transportation are not adopted.
\end{abstract}

Keywords: production, housing, cattle

\section{Introdução}

A bovinocultura de corte representa para o Brasil um relevante papel na economia, se destacando na produção de alimentos de excelente qualidade com menor custo. Neste contexto, o país ocupa posição de destaque no ranking, sendo detentor do segundo maior rebanho mundial de bovino e consequentemente maior produtor de carne bovina, depois dos Estados Unidos, como, também, maior exportador mundial do produto com 205. 292 milhões de cabeças, ficando atrás apenas da Índia, entretanto, este país não produz animais para consumo (BRASIL, 2010).

O consumo de carne vem aumentando significativamente no mundo, portanto a maior preocupação é quanto a atender as exigências do consumidor em relação à qualidade e segurança alimentar do produto e ao bem estar das pessoas e dos animais (LUCHIARI FILHO, 2006).

Alguns procedimentos técnicos e científicos são necessários para se conseguir um ótimo desempenho no bem estar animal e na qualidade da carne bovina, assim o abate humanitário que inicia - se desde o embarque dos animais na fazenda até a sangria na indústria frigorífica deve prevalecer antes 
FONSECA, A.A. et al. Efeito do transporte na qualidade e rendimento da carne. PUBVET, Londrina, V. 8, N. 5, Ed. 254, Art. 1682, Março, 2014.

e durante o abate, tornando-se indispensável para obter um melhor resultado e causar menos estresse aos animais (ROÇA, 2001).

O uso de práticas do bem estar animal proporciona a redução do sofrimento desnecessário promovendo a qualidade de vida aos animais que muitas vezes são tratados ou considerados apenas como simples mercadorias ou produtos comercializáveis e geradores de lucro. Logo, garantir uma morte humanitária aos mesmos dentro dos padrões éticos morais da sociedade e oferecer a população alimentos seguros originados de animais criados em sistemas de produção sustentáveis e ambientalmente corretos se torna um dos maiores desafios da agropecuária mundial (HOLANDA, 2006).

Sendo assim, objetivou-se com essa revisão apresentar um entendimento do efeito do transporte na qualidade e rendimento da carne.

\section{Revisão de literatura}

\subsection{Embarque}

O embarque e o transporte por não fazer parte do ambiente normal dos animais, assim como, também, o manejo no frigorifico antes do abate são considerados os eventos mais estressantes na vida do animal, o que afeta diretamente a qualidade da carne (GOMIDE et al., 2006).

O embarcadouro é a instalação que permite conduzir os animais para dentro da "gaiola" do caminhão ou da carreta. É composto por um corredor com uma rampa no final, que permite os animais alcançarem o piso da "gaiola". As paredes laterais devem ser fechadas para que os animais não se distraiam com o movimento das pessoas ou outros animais do lado externo e, também, para diminuir a projeção de sombras no piso do embarcadouro, que podem fazer os animais empacarem (PARANHOS DA COSTA et al., 2008).

A rampa de acesso ao veiculo em relação ao solo deve apresentar um ângulo de aproximadamente $20^{\circ}$ e nunca superior a esta, sendo ideal um ângulo de $15^{\circ}$ (CORTESI, 1994 citado por JOAQUIM, 2002). A largura dos embarcadouros a serem construídos deve estar entre 0,80 a 0,90m, dependendo das raças e das categorias de animais. No entanto, em casos 
FONSECA, A.A. et al. Efeito do transporte na qualidade e rendimento da carne. PUBVET, Londrina, V. 8, N. 5, Ed. 254, Art. 1682, Março, 2014.

específicos como em fazendas que trabalham com animais muito grandes (Bovino de Elite) é necessário ter embarcadouros mais largos com até 1,00m de largura. Neste mesmo embarcadouro fica difícil manejar outras categorias, isto porque aumenta os riscos dos animais virarem e atrasarem o embarque e, também, de dois animais passarem ao mesmo tempo pelo embarcadouro. Porém, embarcadouros muito estreitos não são recomendados, pois há risco de animais muito grandes não passarem, se machucarem ou ficarem entalados (PARANHOS DA COSTA et al., 2008).

Os mesmos autores relatam que se tratando de bezerros o manejo deve ser mais criterioso isto porque os bezerros viram com frequência dificultando o manejo. Sendo assim, em caso de embarques constantes de bezerros é indicado dispor de estruturas móveis para reduzir a largura do embarcadouro para $0,50 \mathrm{~m}$.

O encarregado do embarque na fazenda juntamente com os motoristas dos caminhões têm em suas mãos a responsabilidade de definir e monitorar quais animais serão embarcados e a densidade ideal de carga a utilizar, sendo recomendado que não sejam embarcados animais em más condições de saúde ou animais que não se encontram habilitados a se manterem em pé durante toda a viagem devido a lesões, fraturas ou fraqueza evidente (PARANHOS DA COSTA et al., 2010). No entanto, o que se observa em relação ao embarque, é que os responsáveis por embarcar os animais nos caminhões de transporte não têm nenhum conhecimento sobre os princípios básicos do bem-estar. Utilizam ferrões ou choques elétricos, comprometendo a qualidade da carcaça, que poderá sofrer lesões durante o processo "forçado" de condução e entrada dos animais no caminhão de transporte (FILHO e SILVA, 2004).

A formação dos lotes de embarque deve ser realizada conforme a capacidade do veiculo, os animais devem ser do mesmo lote, isto porque a mistura de lotes diferentes aumenta a ocorrência de brigas aumentando o estresse entre os animais. Porém, se for inevitável à mistura de animais de diferentes lotes para completar as cargas, estes devem ser agrupados uma semana antes do embarque em pastos ou piquetes, onde tenha mais espaço 
FONSECA, A.A. et al. Efeito do transporte na qualidade e rendimento da carne. PUBVET, Londrina, V. 8, N. 5, Ed. 254, Art. 1682, Março, 2014.

para que possam evitar interações sociais agressivas (PARANHOS DA COSTA et al., 2008). No entanto, Gomide et al. (2006) relatam que é comum a mistura de animais criados em diferentes grupos no embarque. Neste caso, a mistura dos bovinos criados em diferentes lotes devem ser realizada 24 horas antes de serem embarcados nos caminhões. Isto porque a pré mistura dos animais, antes do carregamento, leva uma maior familiaridade, conferindo maior tranquilidade durante o transporte.

De acordo com Oliveira e Silva et al (2002) é importante certificar-se de que não tenha pontas agudas no interior das carrocerias dos caminhões, se os parafusos de fixação estão com as cabeças arredondadas e fixadas de dentro para fora de tal forma que evite arranhões na pele dos animais. Portanto, o embarque só poderá ser realizado após a verificação do veiculo. Não se deve realizar embarque em veículos sujos, quebrados e em mau estado de conservação, o qual oferece riscos ao animal. É necessário verificar, principalmente, se as porteiras da gaiola estão bem abertas, para que os animais possam entrar sem o risco de pancadas no dorso ou na anca (GOMIDE et al., 2006).

\subsection{Transporte}

O transporte dos animais ao estabelecimento de abate apresenta efeitos significativos na qualidade da carne, pois em condições desfavoráveis o sistema de transporte poderá levar à morte dos animais e ser responsável pelas principais contusões observadas na inspeção post mortem, ocasionando estresse aos animais que, consequentemente, irá influenciar a queda do pHpost-mortem (ROÇA, 2001). De acordo com Delezieet al., (2007), isto ocorre por causa da diminuição do glicogênio causada pelo esforço físico e o estresse ocorrido, principalmente, durante o transporte, do qual influencia diretamente na qualidade da carne, devido a não ocorrência de queda satisfatória do pH pós abate, originando a carne Dark, Firm, Dry (DFD).

No momento do abate o $\mathrm{pH}$ da carne é determinado pela quantidade de glicogênio no músculo. As carne com pH em torno de 5,5, geralmente, 
FONSECA, A.A. et al. Efeito do transporte na qualidade e rendimento da carne. PUBVET, Londrina, V. 8, N. 5, Ed. 254, Art. 1682, Março, 2014.

apresentam-se macia, com boa coloração e de paladar saboroso. Baixa proporção de glicogênio no músculo durante o abate, resulta em menor percentual de ácido lático, desta forma o pH último terá uma queda menor, $\mathrm{pH}$ em torno de 5,8 a 6,2 tende a produzir carnes mais escuras, duras e impróprias para consumo. As carnes com pH entre 6,2 e 7,0 são escuras, firmes e secas à cocção e somente poderão ser comercializáveis se manufaturadas (PARANHOS DA COSTA, 2002).

$O$ estresse enfrentado pelos bovinos durante as etapas do pré abate somadas às atividades físicas provoca reações fisiológicas no corpo dos animais resultando em quebra do glicogênio muscular e problemas de queda deficiente do $\mathrm{pH}$ post-mortem que após 24 horas do abate fica acima de 6.0, aumentando as condições favoráveis para a entrada de microrganismos e redução do tempo de prateleira da carne, além disso, o pH final exerce influência na qualidade da carne como diminuição da capacidade de retenção de água, perdas ao cozimento, força de cisalhamento e causa mudança no sabor, suculência, maciez, aroma e cor do produto final (PEREIRA et al., 2011).

Segundo Filho e Silva (2008) o transporte é considerado o evento mais estressante para os bovinos. Os caminhões são as principais formas de transporte dos bovinos para o abate na maioria dos países produtores de carne bovina. Sendo assim, após o embarque é necessário observar certos aspectos como: a densidade de carga do caminhão $(\mathrm{Kg} / \mathrm{m})$, tempo de viagem até o abatedouro (horas), tempo de restrição alimentar e de água, condições ambientais da viagem (temperatura, UR\% e velocidade do vento) e condições das rodovias (trepidações e solavancos), visando um transporte tranquilo sem maiores danos a qualidade da carne.

O motorista desempenha um papel importantíssimo durante o transporte, pois, além de ser responsável por transportar os animais até o seu destino final, ele é responsável pela manutenção das boas condições de conservação e de limpeza de seus veículos, ou seja, livre de pregos ou pontas de parafusos, sem buracos no piso e sem tábuas quebradas. O piso deve ser emborrachado e 
FONSECA, A.A. et al. Efeito do transporte na qualidade e rendimento da carne. PUBVET, Londrina, V. 8, N. 5, Ed. 254, Art. 1682, Março, 2014.

dispor de estrutura antiderrapante. As divisórias devem estar íntegras e limpas e as porteiras devem abrir e fechar sem dificuldades (PARANHOS DA COSTA et al., 2008).

A forma de direção do motorista influencia o bem estar dos animais prevenindo acidentes que, consequentemente, melhora a qualidade da carne. A forma de direção deve ser adaptada às condições da estrada, e, na medida do possível, deve ser evitadas estradas de chão e em más condições de manutenção. Recomenda-se que o motorista seja instruído a parar a cada duas a três horas, a fim de observar as condições dos animais (GOMIDE et al., 2006). O autores ressaltam que a implementação de incentivos financeiros para reduzir contusões e perda de peso deve ser usada para motivar os motoristas.

Durante o transporte é necessário observar as paradas com frequência sendo recomendadas 3 horas para estradas pavimentadas e 2 horas para vias não pavimentadas. O motorista deve ser muito bem instruído a respeito da carga animal que está transportando, esta carga nunca deve ser excessiva e nem razoável, é importante que esteja com uma lotação média do qual visa o conforto dos animais e, consequentemente, à redução nos hematomas da carcaça. É interessante que o veiculo esteja sempre em movimento buscando melhorar a ventilação no interior da gaiola, isto porque se o caminhão ficar muito tempo parado, ocorre um aumento da temperatura com consequente estresse do animal (OLIVEIRA e SILVA et al., 2002).

O espaço ocupado pelos animais, ou seja, a densidade de carga é o principal fator a ser considerado durante o transporte. Este espaço pode ser considerado alto $(600 \mathrm{~kg} / \mathrm{m} 2)$, médio $(400 \mathrm{~kg} / \mathrm{m} 2)$ e baixo $(200 \mathrm{~kg} / \mathrm{m} 2)$. O espaço dentro da carroceria deve permitir que o animal fique em pé, em sua posição natural, sem contato excessivo com os outros animais ou estrutura (GOMIDE et al., 2006).

Segundo Batista de Deus et al. (1999), menores densidades de carga aumentam o espaço e favorece a movimentação dos animais dentro do caminhão oferecendo-Ihes mais conforto, mas por outro lado em espaços 
FONSECA, A.A. et al. Efeito do transporte na qualidade e rendimento da carne. PUBVET, Londrina, V. 8, N. 5, Ed. 254, Art. 1682, Março, 2014.

maiores os animais se machucam batendo nas paredes do veículo de transporte ou chocando-se com os outros. Animais deitados aumentam a extensão das contusões, de modo que se deve mantê-los em pé, mesmo em viagens longas. A alta densidade tem sido responsável pelo aumento das contusões e estresse dos animais, porém, a baixa densidade, também, ocasiona problemas de bem-estar animal, isto porque durante a movimentação do veiculo os animais são jogados contra estruturas da carroceria e outros animais, acarretando a sua queda ao solo, contusões e, ou fraturas. Sendo assim, é recomendada uma densidade média com objetivo de evitar movimentos excessivos (ANDRADE et al., 2008).

Batista de Deus et al. (1999) ao avaliarem o efeito de três distancias de transporte rodoviário de bovinos no metabolismo post mortem, observaram que as maiores distâncias de transporte influenciaram o metabolismo post mortem dos bovinos, aumentando o pH final e diminuindo o teor de lactato do músculo nas $24 \mathrm{~h}$ do post mortem.

Andrade et al. (2008) avaliando a influencia do transporte na ocorrência de lesões em carcaças de bovinos abatidos no Pantanal Sul Matogrossense observaram que as maiores proporções de lesões foram encontradas em animais submetidos ao transporte rodoviário por mais de uma hora e distâncias maiores que $70 \mathrm{~km}$, sendo grande parte em estradas nãopavimentadas.

Com objetivo de evitar o estresse dos animais o transporte deve ser feito o mais rápido possível ao local de abate. Fatores como exposição dos animais a longas distâncias por períodos prolongados, sem um intervalo adequado para descanso somado a choques, freadas bruscas, altas densidades de carga, temperaturas elevadas potencializam possíveis desidratação e brigas dos diferentes lotes de animais. Portanto, é de extrema importância que o manejo operacional, alimentação e fornecimento de água sejam monitorados de forma regular e constante para manter as condições de vida dos animais estáveis e reduzir o estresse (BROOM, 2003). Isto porque o tempo prolongado de transporte provoca estresse aos animais, contribuindo para redução da 
FONSECA, A.A. et al. Efeito do transporte na qualidade e rendimento da carne. PUBVET, Londrina, V. 8, N. 5, Ed. 254, Art. 1682, Março, 2014.

qualidade da carcaça através do aumento do pH final da carne, originando uma maior incidência da carne DFD (GOMIDE et al., 2006).

Mesmo sob boas condições e em viagens curtas, os bovinos mostram sinais de estresse, que se agrava em situações adversas. Animais estressados sofrem, e com isso há maior probabilidade de ocorrerem problemas com a carne, sendo que em situações extremas pode inclusive resultar a morte dos animais, os principais problemas durante os manejos de embarque e transporte são: agressões diretas, formação de novos grupos, instalações inadequadas e transporte inadequado (PARANHOS DA COSTA et al., 2010).

O período de descanso ou dieta hídrica no frigorifico possibilita que os animais recuperem da perturbação surgida durante o deslocamento desde o local de origem até ao estabelecimento de abate (GIL e DURÃO, 1985 citado por ROÇA, 2002). Além da perda de peso vivo que ocorre durante o transporte e espera no matadouro, também ocorre perda de peso da carcaça e, consequentemente, de rendimento do produto final. Calcula-se que a taxa de perda de peso da carcaça seja de 0,75\% a cada 24 horas de transporte. Entretanto, na literatura científica os percentuais são bastante variáveis, encontrando valores inferiores a $1 \%$ a valores de $8 \%$ após 48 horas de privação de alimento e água (GOMIDE et al., 2006).

Segundo os mesmos autores a desidratação do animal é o principal fator envolvido nas perdas de peso durante o transporte, desta forma, o seu acesso à água após jornadas muito longas permite redução no percentual de perda, refletindo em carcaças mais pesada. O uso de soluções eletrolíticas na água disponível para o gado no matadouro tem sido sugerido para reduzir não somente as perdas de peso, mas, também, a incidência de cortes DFD, por atenuar as mudanças fisiológicas a que o animal é submetido antes do abate.

\subsection{Desembarque}

O processo de desembarque é mais simples, no entanto merece atenção. É necessário organizar a chegada dos animais, definindo o número de animais que serão alojados e as instalações devem ser preparadas para recebê-los, 
FONSECA, A.A. et al. Efeito do transporte na qualidade e rendimento da carne. PUBVET, Londrina, V. 8, N. 5, Ed. 254, Art. 1682, Março, 2014.

garantindo conforto aos animais. Com tudo organizado, inicie o manejo, orientando o motorista a encostar bem o caminhão no desembarcadouro. Antes de abrir a porteira do caminhão observe se não há nenhum animal caído. Se for o caso levante-o, primeiro com o uso de aboios (sem gritar), se não for o suficiente suba na lateral e tente movimentar o animal. Somente utilize o bastão elétrico em ultimo caso e sempre respeitando a regra de não utilizar o choque em partes sensíveis do animal (PARANHOS DA COSTA et al., 2008).

Durante o desembarque dos animais no abatedouro os procedimentos deverão ser basicamente os mesmos realizados durante o embarque na fazenda, ou seja, evitar o uso de bastões de choque ou ferrões para forçar os animais a descer do caminhão. É de extrema importância que logo após o desembarque no abatedouro, os animais sejam alojados no curral de espera, onde permanecerão por um tempo suficiente para que se acalmem e descansem da viagem, antes de prosseguirem para as próximas etapas do abate (PEREIRA, 2006).

Segundo Batista de Deus et al. (1999) os animais cansados originam carne com menor tempo de prateleira, em virtude do desenvolvimento incompleto da acidez muscular e consequente invasão precoce da flora microbiana. Essa carne mostra-se escura e pouco brilhante, dando a impressão de uma sangria deficiente. A coloração indesejada é atribuída às alterações físico-químicas do músculo e decréscimo da oxigenação da hemoglobina. Sendo assim, não é recomendado abater o animal imediatamente após a sua chegada ao frigorífico.

O artigo 110 do RIISPOA (Regulamentação de Inspeção Industrial e Sanitária de Produtos de Origem Animal) estabelece que os animais devam permanecer em descanso, jejum e dieta hídrica nos currais de espera por 24 horas, podendo este período serem reduzidos quando a viagem não for superior a 2 horas e os animais serem procedentes de campos próximos, mercados ou feiras, sob controle sanitário permanente. No entanto, o repouso, 
FONSECA, A.A. et al. Efeito do transporte na qualidade e rendimento da carne. PUBVET, Londrina, V. 8, N. 5, Ed. 254, Art. 1682, Março, 2014.

em hipótese alguma poderá ser inferior a 6 horas, a não ser em algum caso que a Inspeção Federal julgar necessário (BRASIL, 1952).

\section{Considerações finais}

No manejo pré abate dos bovinos é de extrema importância o conhecimento desde o embarque na propriedade até o momento do abate, pois este manejo garante a qualidade da carne $e$, consequentemente, maior rendimento da carcaça. Desta forma o transporte torna-se uma etapa fundamental na produção de bovinos de corte, visto que só a genética, manejo sanitário e o manejo alimentar não garantem a qualidade e o rendimento da carcaça se boas praticas no transporte não forem adotadas.

\section{Referências bibliográficas}

ANDRADE, E. N. DE et al. Ocorrência de lesões em carcaças de bovinos de corte no Pantanal em função do transporte. Revista Ciência Rural, v.38, n.7, 2008.

BATISTA DE DEUS, J. C.; SILVA, W. P. DA; SOARES, G. J. D. Efeito da distância de transporte de bovinos no metabolismo post mortem. Revista Brasileira de Agrociência, v.5 no2, p.152-156, 1999.

BRASIL. Ministério da Agricultura, Pecuária e Abastecimento. Departamento de Defesa e Inspeção Agropecuária. Regulamento de Inspeção Industrial e Sanitária de Produtos de Origem Animal. Rio de Janeiro, 1952. 154p. Disponível em: <http://www.agricultura.gov.br/arq_editor/file/Aniamal/MercadoInterno/Requisitos/Regulame ntoInspecaoIndustrial.pdf $>$. Acesso em: 24/05/2012.

BRASIL. IBGE - Instituto brasileiro de geografia e estatística. Efetivo nacional de bovinos cresce $1,5 \%$ em 2009. 2010. Disponível em: <http://www.ibge.gov.br/home/presidencia/noticias/noticia_visualiza.php?id_noticia=1761\&id _pagina $=1 .>$.Acesso em: 21/05/2012.

BROOM, D. M; MOLENTO, C. F. M. Bem-estar animal: conceito e questões relacionadas Revisão. Archives of Veterinary Science, v.9, n.2, p.1-11, 2004.

DELEZIE, E.; SWENNEN, Q.; BUYSE, J.; DECUYPERE, E.The Effect of Feed Withdrawal and Crating Density in Transit on Metabolism and Meat Quality of Broilers at Slaughter Weight.Poultry Science, 2007. v. 86, p. 1414-1423, 2007.

FERREIRA, G. B. Avaliação do tempo de transporte e descanso de bovinos e seus efeitos na qualidade da carne em carcaças estimuladas eletricamente. 2005. 98p. Dissertação (Mestrado em Medicina Veterinária), Universidade Federal Fluminense, Niterói, 2005.

FILHO, A. D. B.; SILVA, I. J. O. Abate humanitário: ponto fundamental do bem-estar animal. Revista nacional da carne. São Paulo, v.328, p.36-44, 2004. 
GOMIDE, L. A. DE. M.; RAMOS, E. M.; FONTES, P. R. Tecnologia de abate e tipificação de carcaças. Viçosa: UFV, 2006, 370p.

HOLANDA, DE M. C. R. Conceitos em bem-estar animal. In: ENCONTRO DE BIOÉTICA E BEMESTAR ANIMAL DO AGRESTE MERIDIONAL PERNAMBUCANO, 1, 2006, Garanhuns-PE. Anais...Garanhus-PE: Universidade Federal Rural de Pernambuco, 2006.

JOAQUIM, C. F. Efeitos da distância de transporte em parâmetros post-mortem de carcaças bovinas. 2002. 79p. Dissertação (Mestrado em Medicina Veterinária), Universidade Estadual Paulista - Faculdade de medicina veterinária e zootecnia, Botucatu, 2002.

LUCHIARI FILHO, A. A. Produção de Carne Bovina no Brasil Qualidade, Quantidade ou Ambas. In: SIMPÓSIO SOBRE DESAFIOS E NOVAS TECNOLOGIAS NA BOVINOCULTURA DE CORTE, 2 , 2006, Brasília. Anais... Brasília: Faculdade de Zootecnia e Engenharia de Alimentos - USP, 2006.

OLIVEIRA E SILVA, A. C. de et al. Avaliação do transporte do rebanho bovino e seus reflexos na qualidade da carne e do couro brasileiro. In: XXII ENCONTRO NACIONAL DE ENGENHARIA DE PRODUÇÃO. Anais... ABEPRO: Curitiba, 2002.

PARANHOS DA COSTA, M. J. R; COSTA E SILVA, E. V; CHIQUITELLI NETO, M; ROSA, M. S. Contribuição dos estudos de comportamento de bovinos para implementação de programas de qualidade de carne. In: F. DA S. ALBUQUERQUE (ORG.)- ENCONTRO ANUAL DE ETOLOGIA, 20, 2002, Natal. Anais... Natal: Sociedade Brasileira de Etologia, 2002. p. $71-89$.

PARANHOS DA COSTA, M. J. R.; SPIRONELLI, A. L. G.; QUINTILIANO, M. H. Boas práticas de manejo - embarque. Jaboticabal: Funep, 2008, 35 p.

PARANHOS DA COSTA, M. J. R; QUINTILIANO, M. H; TSEIMAZIDES, S. P. Boas Práticas de Manejo Transporte. Jaboticabal: Funep, 2010. 56p.

PEREIRA, L. S. et al. Efeito da distância e do tempo de descanso sobre o ph final de carcaças bovinas. Veterinária e Zootecnia, v.18, (4 Supl. 3): 1149, 2011.

ROÇA, R. O. Abate humanitário: manejo ante-mortem. Revista TeC Carnes, Campinas, v.3, n.1, p.7-12, 2001.

ROÇA, R. DE O. Abate humanitário de bovinos. In: CONFERÊNCIA VIRTUAL GLOBAL SOBRE PRODUÇÃO ORGÂNICA DE BOVINOS DE CORTE, 1, 2002, Botucatu. Anais... Botucatu: Universidade Estadual Paulista "Julio de Mesquita Filho", 2002. p. 1-15. 